\title{
249 SPORTS SOCIOLOGY IN DIFFERENT COMMUNITIES
}

Sarita Yadav Lecturer, Department of Physical Education, Arya Kanya Mahavidyalaya, Hardoi, Uttar Pradesh, India

10.1136/bjsm.2010.078725.249

The sports sociology community has a real opportunity to break out of the academic ghetto, eschew excessively coded and obscure language, and fight to become part of the general discourse of sports conversation, both on campuses and in the 
broader sports world. Sport sociology can be valued as a discipline within sport sciences, within sociology and within the world of sport which it analyses and serves. Among others, point to the high status which society accords to the natural sciences, and note that this is also mirrored in physical education and sport sciences. The central purpose of sport sciences is to study that conglomerate of mind, body and spirit which is the embodiment of sport and a wide range of physical activities. That embodiment is, inevitably, a social being - a member of society. Sport sociology can best be described as a late adolescent/early adult. Arguably, where sport sociology has been less successful is in its attempts to gain greater acceptance among sports practitioners, and it is that issue which underpins the discussion. The primary purpose of action knowledge is to inform policy and planning and, to this end, action research is identified as a way of ensuring that policy and implementation are compatible. professionals in sport: 'teachers, coaches, administrators, journalists and executives...certainly need it to better understand their own position and action in modern sport'. We would wish to add sports participants/performers themselves to the list. Sport sociologists to work more closely with the sports community, which 'requires applied sport sociology to be the enterprise of a disputatious, many-valued community of scholars who work in collaboration with the persons, groups and communities. Sport sociology, more generally, has tended to include a wide range of sport sociologists are beginning to be asked for information by public and professional groups. He envisages a future role for sport sociology 'interpreting the reciprocal influences of sport in society and society in sport' methodological and theoretical paradigms. An applied sociology of sport based on the roles and skills required to undertake applied research. 